\title{
Immune biomarkers to predict SARS-CoV-2 vaccine effectiveness in patients with hematological malignancies
}

\author{
Luis-Esteban Tamariz-Amador ${ }^{1,9}$, Anna Martina Battaglia ${ }^{1,2,9}$, Catarina Maia ${ }^{1,9}$, Anastasiia Zherniakova (iD ${ }^{1,3,9}$, Camila Guerrero (iD ${ }^{1,9}$, \\ Aintzane Zabaleta ${ }^{1}$, Leire Burgos ${ }^{1}$, Cirino Botta (iD) ${ }^{2}$, Maria-Antonia Fortuño ${ }^{1}$, Carlos Grande (iD) ${ }^{1}$, Andrea Manubens ${ }^{1}$, \\ Jose-Maria Arguiñano ${ }^{4}$, Clara Gomez ${ }^{5}$, Ernesto Perez-Persona ${ }^{6}$, Iñigo Olazabal ${ }^{7}$, Itziar Oiartzabal ${ }^{8}$, Carlos Panizo ${ }^{1}$, Felipe Prosper (D) ${ }^{1}$, \\ Jesus F. San-Miguel (D) ${ }^{1}$, Paula Rodriguez-Otero ${ }^{1}$, Esperanza Martín-Sánchez (D) ${ }^{1,10 凶}$, Bruno Paiva (D) ${ }^{1,10 \bowtie}$ and The Asociación Vasco- \\ Navarra de Hematología y Hemoterapia (ASOVASNA) Cooperative Group*
}

(c) The Author(s) 2021

There is evidence of reduced SARS-CoV-2 vaccine effectiveness in patients with hematological malignancies. We hypothesized that tumor and treatment-related immunosuppression can be depicted in peripheral blood, and that immune profiling prior to vaccination can help predict immunogenicity. We performed a comprehensive immunological characterization of 83 hematological patients before vaccination and measured $\lg M$, $\lg G$, and $\lg A$ antibody response to four viral antigens at day +7 after second-dose COVID-19 vaccination using multidimensional and computational flow cytometry. Health care practitioners of similar age were the control group ( $n=102)$. Forty-four out of 59 immune cell types were significantly altered in patients; those with monoclonal gammopathies showed greater immunosuppression than patients with B-cell disorders and Hodgkin lymphoma. Immune dysregulation emerged before treatment, peaked while on-therapy, and did not return to normalcy after stopping treatment. We identified an immunotype that was significantly associated with poor antibody response and uncovered that the frequency of neutrophils, classical monocytes, CD4, and CD8 effector memory CD127low T cells, as well as naive CD21+ and lgM+D+ memory $B$ cells, were independently associated with immunogenicity. Thus, we provide novel immune biomarkers to predict COVID-19 vaccine effectiveness in hematological patients, which are complementary to treatment-related factors and may help tailoring possible vaccine boosters.

Blood Cancer Journal (2021)11:202; https://doi.org/10.1038/s41408-021-00594-1

\section{INTRODUCTION}

The novel coronavirus disease 2019 (COVID-19) pandemic has spread throughout the world, with over 249 million confirmed cases globally and more than 5 million deaths as of November 2021 (https://covid19.who.int/). Compared with the general population, cancer patients are at greater risk of serious COVID19-related complications and fatal outcome [1, 2]. Higher mortality was observed in hematological patients when compared to those with solid tumors [3-6], which likely reflects immune impairment from the underlying blood cancer as well as therapies that disable innate, $B$, and T-cell immunity [5, 7-10]. According to large studies, nearly one-third of individuals with hematological malignancies have died with COVID-19 [11-13]. Thus, effective vaccination against severe acute respiratory syndrome coronavirus 2 (SARS-CoV-2) is of utmost importance to prevent COVID-19 in these patients.

There was great concern that individuals with cancer may not mount a robust protective immune response to SARS-CoV-2 vaccination and initial reports investigating vaccine effectiveness in this population showed that antibody production was more likely to occur in patients with solid tumors than in those with hematological malignancies [14-16]. Subsequent studies across the spectrum of hematological malignancies uncovered remarkable heterogeneity in response to vaccination, with the poorest rates of seropositivity being generally observed in patients with B-cell chronic lymphocytic leukemia (CLL), non-Hodgkin lymphoma, and multiple myeloma (MM) [17]. By contrast, seroconversion was higher in cases with acute leukemia, chronic myeloid leukemia, myelodysplastic syndromes, and Hodgkin lymphoma $[18,19]$. After these initial observations, larger and disease-specific studies in patients with B-cell and plasma cell (PC) disorders were most recently reported.

The efficacy of SARS-CoV-2 vaccine in CLL patients was $39.5 \%$ and $75 \%$ in two large Israeli and UK studies [20, 21]. In both cohorts, increased rates of seronegativity were associated with immunoparesis and the use of Bruton's tyrosine kinase inhibitors.

\footnotetext{
${ }^{1}$ Clinica Universidad de Navarra, Centro de Investigacion Medica Aplicada (CIMA), IDISNA, CIBERONC, Pamplona, Spain. ${ }^{2}$ Department of Experimental and Clinical Medicine, "Magna Graecia", University of Catanzaro, Catanzaro, Italy. ${ }^{3}$ Russian Research Institute of Hematology and Transfusiology, Saint-Petersburg, Russian Federation. ${ }^{4}$ Complejo

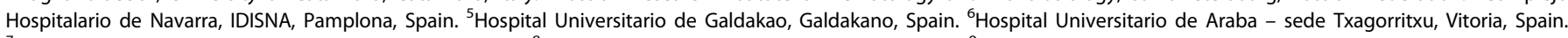
${ }^{7}$ Hospital Universitario de Donostia, San Sebastian, Spain. ${ }^{8}$ Hospital Universitario de Cruces, Bilbao, Spain. ${ }^{9}$ These authors contributed equally: Luis-Esteban Tamariz-Amador,

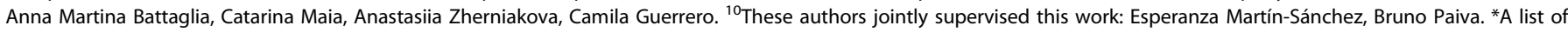
authors and their affiliations appears at the end of the paper. ${ }^{凶}$ email: emartinsan@unav.es; bpaiva@unav.es
} 
By contrast, the negative impact of venetoclax and anti-CD20 therapy was not consistent. In patients with B-cell lymphoma, seronegativity was found to be associated with indolent vs. aggressive subtypes and with B-cell suppressive therapies $[18,22,23]$. Nonetheless, poor serological responses were observed in some patients who did not receive therapy in the past 2 years [18]. In MM, clinically relevant antibody responses were generally observed in $\geq 50 \%$ of patients $[18,24-30]$. Although suboptimal seroconversion was common on active treatment, discordant results on the impact of anti-CD38 and anti-BCMA antibodies, as well as steroids were reported $[26-28,30]$.

The great heterogeneity observed in the efficacy of vaccines for COVID-19 among hematological patients is probably associated with both therapy-related immunosuppression and disease-related immune dysregulation. Thus, we conducted a prospective study to determine the immune landscape of patients with a mature B-cell and PC neoplasm prior vaccination and its relationship with antibody response after two doses of SARS-CoV-2 vaccine. We hypothesized that immune profiling prior vaccination could be complementary to other clinical features in the identification of hematological patients at risk of weak immunogenicity.

\section{PATIENTS AND METHODS \\ Study design}

A total of 83 patients with hematological malignancies and 102 health care practitioners (HCPs), vaccinated between January and June 2021, were studied (Fig. 1A). Only HCP older than 50 were included as the control group to match the expected age of patients. All subjects had no documented SARS-CoV-2 infection. Peripheral blood and serum were collected prior to the first dose, at days 7 and 14 after the first dose, at day 7 after the second-dose and at day 100 after the first-dose vaccination. The study was approved by the Ethics Committee of the Comunidad Foral de Navarra (2021.006) and was conducted per the ethical principles of the Declaration of Helsinki. All HCP and patients provided written informed consent prior enrollment in the study. Samples and data from subjects included in the study were provided by the Biobank of the University of Navarra and were processed following standard operating procedures approved by the Ethical and Scientific Committees. No data were collected regarding vaccination side effects or toxicities, as this was outside the scope of the study.

\section{Assessment of serological response}

Antibody response at day 7 after second-dose vaccination and at day 100 after first-dose vaccination (in $100 \mathrm{HCP}$ and 79 patients) was assessed using a CE-IVD serological SARS-CoV-2 multiplex bead-based flow cytometry immunoassay (Immunostep SL, Salamanca, Spain) (Fig. 1B) [31]. It allows the simultaneous and quantitative detection of specific $\lg M$, $\mathrm{IgG}$, and $\lg \mathrm{A}$ antibodies to four different viral antigens present in serum: (1) the receptor-binding domain (RBD) of the S-glycoprotein; (2) the stable trimer of the spicule (S) glycoprotein; (3) the nucleocapsid (N) protein; and (4) the main virus protease (Mpro). Detection of antibodies against the $\mathrm{N}$ and Mpro antigens allows the identification of individuals infected with SARS-CoV-2 before or during vaccination. Thus, the assay enabled the accurate discrimination between vaccinated and naturally infected individuals (i.e., negative and positive for both antigens, respectively).

First, samples were diluted $(1: 20$ and $1: 200$ to respectively measure $\lg \mathrm{M} / \lg A$ and $\lg G$ antibodies in $\mathrm{HCP} ; 1: 10$ and $1: 100$ to respectively measure IgM/lgA and IgG antibodies in patients) before incubation with beads, at which stage there is binding of antigen-specific antibodies to the respective proteins that are coating the beads. Each bead has a unique fluorescence intensity pattern and is coated with one of the SARSCoV-2 antigens enumerated above (RBD, S, N, and Mpro). After washing to remove unbound antibodies, fluorophore-conjugated anti-human IgM (PE-Cy7), IgG (fluorescein isothiocyanate, FITC), and IgA (PE) were added to quantify antigen-specific antibodies bound to beads. After another washing step, beads were suspended and the fluorescence intensity was measured in the PE-Cy7, FITC, and PE channels, which is proportional to the amount of $\operatorname{lgM}, \operatorname{lgG}$, and $\lg A$ antibodies present in serum, respectively. Samples were analyzed in a CytoFlex LX (Beckman Coulter
[BC] Life Sciences, IN) using the CytExpert v2.3 software (BC) and in an Aurora (Cytek Biosciences, CA) using the SpectroFlo v3.0.0 software (Cytek). Antibody indexes were calculated following the manufacturer's formula [(mean fluorescence intensity of the sample/mean fluorescence intensity of the negative control provided in the kit) $\times 10$ ] and detection of antibodies was considered positive if antibody indexes were $\geq 12$. The assay is calibrated following the WHO First International Standard for Anti-SARS-CoV-2 Human Immunoglobulin (NIBSC Code 20/136). Thus, we reported the concentration of IgG in international units $(\mathrm{IU} / \mathrm{mL})$ against RBD or in binding antibody units $(B A U / \mathrm{mL})$ against $S$ viral antigens. The dilution range to obtain a lineal regression model $(r \geq 0.99)$ was of $1: 8$ to $1: 16,384$.

\section{Immune profiling}

Peripheral blood was collected in EDTA containing tubes and processed within $24 \mathrm{~h}$ following the EuroFlow lyse-wash-and-stain protocol (adjusted to $10^{6}$ nucleated cells) [32]. Eight-color monoclonal antibody combinations (Supplemental Table 1) were developed to enumerate major lymphocyte and myeloid compartments (Fig. 1C) and characterize the relative distribution of granulocytes, antigen-presenting cells (APCs), T-cell, and B-cell subsets within each of these compartments (Fig. 1C-E). Overall, 59 immune cell types were systematically evaluated in peripheral blood of hematological patients and HCP (Supplemental Fig. 1 and Supplemental Table 2). Samples were measured in a FACSLyric flow cytometer (Beckton Dickinson Biosciences [BD], San Jose, CA, USA) using FACSuite v1.3.0.6137 software (BD).

\section{Computational flow cytometry analysis}

Data were analyzed using FlowCT, a semi-automated workflow developed for deconvolution of immunophenotypic data and objective reporting on large datasets [33]. Briefly, FlowCT starts by creating a matrix with expression data generating a SingleCellExperiment object and correcting possible discrepancies in markers' nomenclature. Subsequently, it performs internal data quality control and normalization, and automated clustering followed by dimensionality reduction to visualize clusters' identity before manual annotation. This step is completed using the Infinicyt software (Infinicyt v2.0; Cytognos SL, Salamanca, Spain). Afterwards, sub-clustering of APC, T, and B cells was performed. Comma-separated value files with population abundances were finally exported to evaluate statistical correlations and differences across groups.

\section{Statistical analysis}

Immune profiles and seroconversion were compared between HCP vs. patients, and between groups of patients using proportions of immune cell types and antibody indexes or concentrations. The Kruskal-Wallis and Mann-Whitney tests were performed to estimate the statistical significance observed between groups and the $X^{2}$ and Mann-Whitney $U$-tests were performed to test distributions between immunotypes resulting from unsupervised clustering. Logistic regression was performed to analyze the relationship between clinical and immune covariates in predicting antibody response to SARS-CoV-2 vaccination (defined as $\geq 553.5 \mathrm{IU} / \mathrm{mL}$ anti-RBD lgG) in hematological patients. First, cutoffs were calculated for the 59 immune cell types to maximize the area under the receiver operating characteristics curve (AUC). $X^{2}$ and odds ratio univariate analyses were subsequently performed to filter variables associated with antibody response $(P<0.1)$. Further feature selection for immune covariates was performed using lasso regularization for logistic regression (scikit-learn), where coefficients of nonsignificant or multi-colinear variables are shrunk to 0 . A logistic regression machine learning model was generated for six immune and two clinical covariates and evaluated using fourfold cross-validation.

All statistical analyses were performed using the GraphPad Prism (version 7, San Diego, CA, USA), SPSS (version 25.0.0, IBM, Chicago, IL, USA), and $R$ (version 4.0.0) software. Machine learning analyses were performed using Python (version 3.8.6) and scikit-learn (version 0.23.2). P-values of $<0.05$ were considered statistically significant.

\section{RESULTS}

\section{Characteristics of hematological patients and HCP}

The median age of patients and HCP was 55 (Table 1). There was an increased proportion of female HCP, whereas other variables such as body mass index $>30$ and comorbidities such diabetes, 


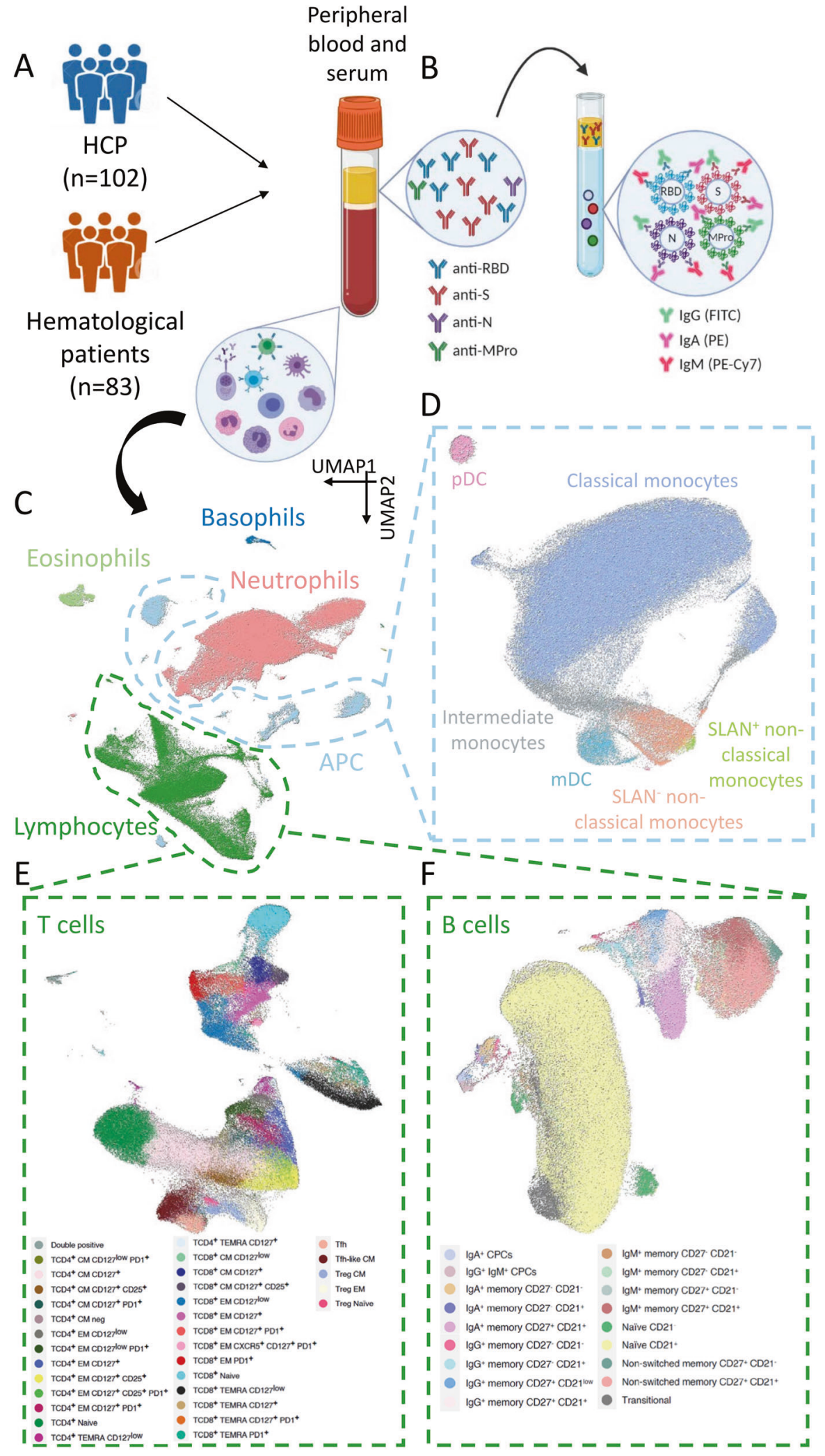

hypertension, and autoimmune disease were generally balanced between patients and HCP. All but one patient and seven HCP received mRNA SARS-CoV-2 vaccines; $59 \%$ of patients were administered BNT162b2, whereas $66 \%$ of HCP were vaccinated with mRNA-1273 (Table 1).
Of the 83 patients enrolled, seven had Hodgkin lymphoma and the remaining 76 had a mature B-cell or PC neoplasm (Table 2). There were seven cases diagnosed with CLL, 25 with indolent and 16 with aggressive non-Hodgkin lymphoma subtypes and 28 patients had a monoclonal gammopathy 
Fig. 1 Study design. A Peripheral blood and serum from 83 patients with hematological malignancies and 102 health care practitioners (HCP) were analyzed. B Antibody response at day 7 after the second-dose vaccination was measured using a CE-IVD serological SARS-CoV-2 multiplex bead-based flow cytometry immunoassay. It allows the simultaneous and quantitative detection of specific IgM, IgG, and IgA antibodies to four different antigens present in serum: (1) the receptor-binding domain (RBD) of the S-glycoprotein; (2) the stable trimer of the spicule (S) glycoprotein; (3) the nucleocapsid (N) protein; and (4) the main virus protease (Mpro). Detection of antibodies against the $\mathrm{N}$ and Mpro antigens allows the identification of individuals infected with SARS-CoV-2 prior or during vaccination. C Immune profiling of hematological patients and HCP prior vaccination was performed using multidimensional and computational flow cytometry. A total of 59 immune cell types were systematically measured in peripheral blood, including basophils, eosinophils, neutrophils, antigen-presenting cells (APC) and lymphocytes. D APC were sub-clustered into classical, intermediate, SLAN - and SLAN+ non-classical monocytes, as well as plasmacytoid and myeloid dendritic cells ( $\mathrm{PDC}$ and $\mathrm{mDC}$, respectively). E Sub-clustering of T cells into 32 subsets related to antigendependent differentiation, as well as activation and exhaustion phenotypes in helper and cytotoxic compartments. $\mathbf{F}$ Sub-clustering of B cells into 18 subsets related to antigen-dependent differentiation. CM, central memory; EM, effector memory; TEMRA, effector memory T cells re-expressing CD45RA; Tfh, follicular helper T cells; Treg, regulatory T cells; CPCs, circulating plasma cells.

Table 1. Characteristics and type of vaccine for COVID-19 administered to health care practitioners (HCPs) and patients with hematological malignancies.

\begin{tabular}{|c|c|c|}
\hline Characteristics & $\begin{array}{l}\text { HCP } \\
(N=102)\end{array}$ & $\begin{array}{l}\text { Patients } \\
(N=83)\end{array}$ \\
\hline Age, median (range), years & $55(50-69)$ & $55(21-85)$ \\
\hline Male, no. (\%) & $10(10 \%)$ & 45 (54\%) \\
\hline \multicolumn{3}{|l|}{ Comorbidities, no. (\%) } \\
\hline Any & $25(24.5 \%)$ & $21(25 \%)$ \\
\hline Body mass index $>30$ & $11(11 \%)$ & $13(16 \%)$ \\
\hline Diabetes & $0(0 \%)$ & $7(8 \%)$ \\
\hline Hypertension & $8(8 \%)$ & $11(13 \%)$ \\
\hline Autoimmune disease & $7(7 \%)$ & $3(4 \%)$ \\
\hline \multicolumn{3}{|l|}{ Hematological malignancy, no. (\%) } \\
\hline B-cell lymphoproliferative disorders & - & $48(58 \%)$ \\
\hline Monoclonal gammopathies & - & $28(34 \%)$ \\
\hline Hodgkin lymphoma & - & $7(8 \%)$ \\
\hline \multicolumn{3}{|l|}{ Type of vaccine, no. (\%) } \\
\hline BNT162b2 & $28(27.4 \%)$ & $49(59.0 \%)$ \\
\hline mRNA-1273 & $67(65.7 \%)$ & $33(39.8 \%)$ \\
\hline ChAdOx1 & $7(6.9 \%)$ & $1(1.2 \%)$ \\
\hline
\end{tabular}

(one monoclonal gammopathy of undetermined significance, two smoldering and 25 active MM). The median time from diagnosis was 3 years (range, 0.2-26). Although the scope of the study was in patients with a mature B-cell or PC neoplasm, those with Hodgkin lymphoma were not excluded from the study population due to less information on the vaccine effectiveness in this disease. In addition, it allowed the comparison of immune profiles in patients with Hodgkin lymphoma vs. patients with a B-cell lymphoproliferative disorder or a monoclonal gammopathy.

At the time of vaccination, $17(20.5 \%)$ patients had never received anti-tumor treatment, 17 (20.5\%) were on-therapy, and 49 (59\%) were off. The median number (and range) of lines in patients on and off-treatment was $2(1-4)$ and 1 (1-5), respectively. Among treated patients, 54/66 (82\%) were in complete response $(C R)$ and $12 / 66(18 \%)$ in less than $C R$ (Table 2).

\section{Immune landscape of hematological patients and HCP}

When compared to HCP, 44 of the 59 (75\%) immune cell types evaluated in peripheral blood were significantly altered in patients belonging to at least one of the three main disease categories: B-cell lymphoproliferative disorders (28/59, 47\%), monoclonal gammopathies (43/59, 73\%), and Hodgkin lymphoma $(12 / 59,20 \%)$. The B-cell compartment was similarly
Table 2. Seroconversion in 83 patients with hematological malignancies.

\begin{tabular}{|c|c|}
\hline Disease & Patients \\
\hline B-cell lymphoproliferative disorders & $36 / 48$ \\
\hline Chronic lymphocytic leukemia & $4 / 7$ \\
\hline Indolent non-Hodgkin lymphoma & $18 / 25$ \\
\hline Follicular lymphoma & $10 / 14$ \\
\hline Marginal zone lymphoma & $4 / 6$ \\
\hline MALT lymphoma & $0 / 1$ \\
\hline Lymphoplasmacytic lymphoma & $3 / 3$ \\
\hline Hairy-cell leukemia & $1 / 1$ \\
\hline Aggressive non-Hodgkin lymphoma & $14 / 16$ \\
\hline Diffuse large B-cell lymphoma & $9 / 10$ \\
\hline Cutaneous B-cell lymphoma & $2 / 3$ \\
\hline Burkitt lymphoma & $2 / 2$ \\
\hline Mediastinal B-cell lymphoma & $1 / 1$ \\
\hline Monoclonal gammopathies & $17 / 28$ \\
\hline MGUS & $1 / 1$ \\
\hline Smoldering multiple myeloma & $2 / 2$ \\
\hline Active multiple myeloma & $14 / 25$ \\
\hline Hodgkin lymphoma & $6 / 7$ \\
\hline \multicolumn{2}{|l|}{ Treatment } \\
\hline Never received & $14 / 17$ \\
\hline On & $6 / 17$ \\
\hline Off & $39 / 49$ \\
\hline \multicolumn{2}{|l|}{ Lines of therapy } \\
\hline 1 & $35 / 44$ \\
\hline 2 or more & $10 / 22$ \\
\hline \multicolumn{2}{|l|}{ Previous treatment } \\
\hline Anti-CD20 & $22 / 27$ \\
\hline Anti-CD38 & $6 / 12$ \\
\hline Immunomodulatory drugs & $11 / 22$ \\
\hline Autologous stem cell transplantation & $14 / 20$ \\
\hline \multicolumn{2}{|c|}{ Depth of response before vaccination in treated patients } \\
\hline Complete response & $54 / 66$ \\
\hline No complete response & $12 / 66$ \\
\hline
\end{tabular}

skewed in patients with a B-cell and a PC neoplasm vs. HCP. Those with monoclonal gammopathies showed additional redistribution of CD4 and CD8 T-cell subsets, as well as of APC (Fig. 2 and Supplemental Fig. 2). All three regulatory T (Treg) cell types identified in this study were significantly reduced in cases with a B-cell and PC neoplasm; two follicular 

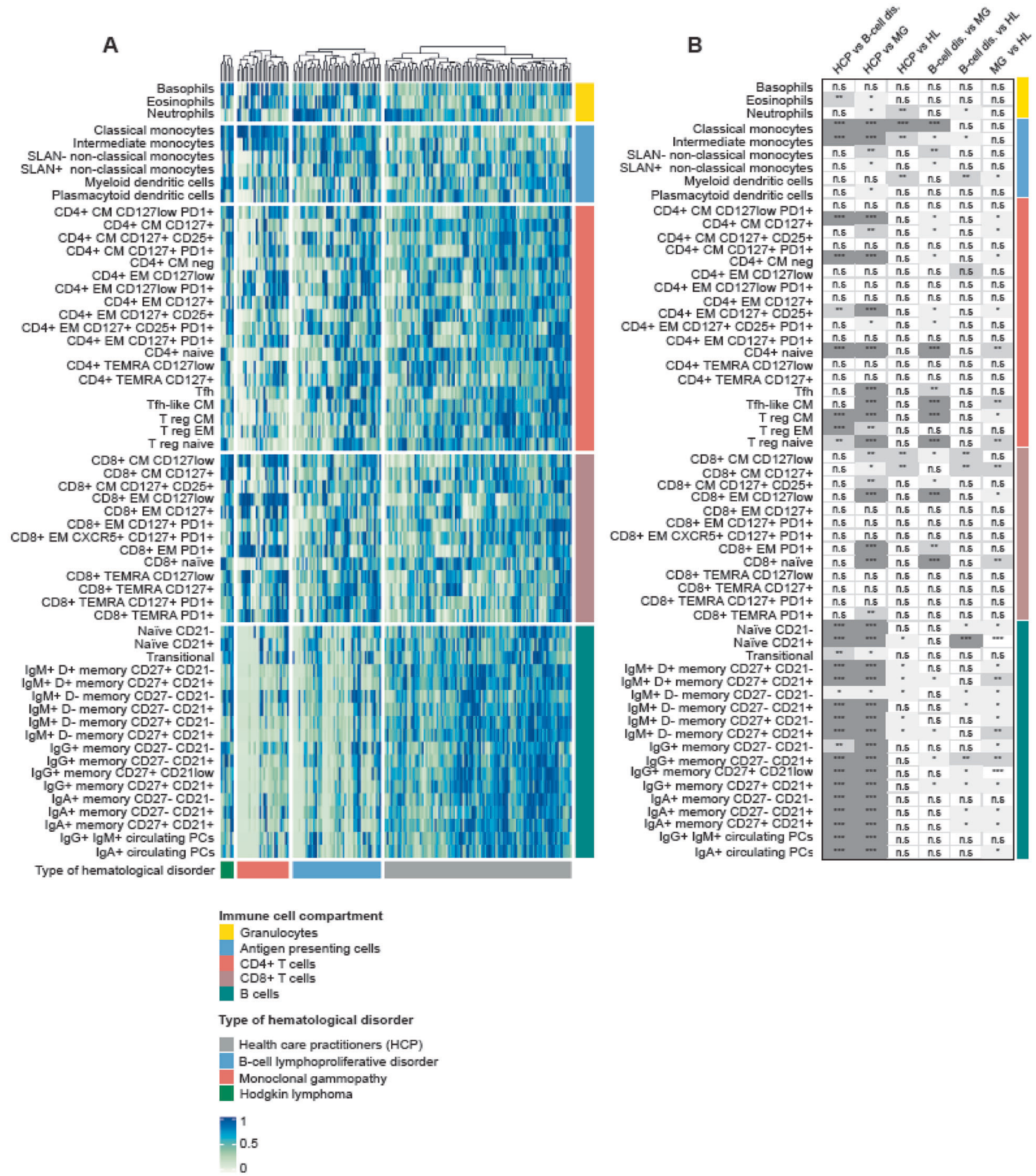

Fig. 2 The immune landscape of hematological patients and HCP. A Supervised clustering of 83 patients with hematological malignancies and 102 health care practitioners (HCP), based on the percentile distribution of 59 immune cell types in peripheral blood that were categorized into five groups: granulocytes, antigen-presenting cells (APC), CD4, and CD8 T cells and B cells. Patients were grouped based on the diagnosis of a B-cell lymphoproliferative disorder (B-cell dis.), monoclonal gammopathies (MG), and Hodgkin lymphoma (HL). B Statistical significance of differences across groups (with graphical representation of such differences in Supplemental Fig. 2). CM, central memory; EM, effector memory; Treg, $T$ regulatory cells; Tfh, $T$ follicular-like; TEMRA, terminally effector memory CD45RA $+; P C$, plasma cells. ${ }^{*} P<0.05$; ${ }^{* *} P<0.01 ;{ }^{* *} P<0.001 ;$ n.s., not significant.

helper (Tfh) cell types were additionally skewed in those with monoclonal gammopathies. Patients with Hodgkin lymphoma displayed mild deregulation of the B- and T-cell compartments, and the most significant alterations were observed in APC. Interestingly, a significant increment of classical and intermediate monocytes was found across hematological patients.

\section{Tumor-related immune dysregulation and therapy-related immunosuppression}

Next, we analyzed the immune status of HCP compared to that of patients that had never received anticancer therapy (i.e., tumorrelated immune dysregulation), were on-treatment or had finalized their regimen (i.e., therapy-related immunosuppression). 
When comparing the relative distribution of the 59 immune cell types to that of HCP, patients that were on and off-treatment showed more frequent alterations than those that were never treated (39/59 [66\%], 33/59 [56\%], and 20/59 [34\%], respectively). An increased frequency of classical and intermediate monocytes was, once more, found across hematological patients, whereas other granulocytic cell types and APC were less altered (Fig. 3 and Supplemental Fig. 3). The antigen-dependent differentiation of CD4 and CD8 T cells was frequently altered in patients on and offtreatment, whereas it was similar between HCP and patients that were never treated. The most significant differences within the T-cell compartment were observed in CD4 and CD8 naive and central memory subsets, as well as in Treg and Tfh cell types. Alterations found in 13 out of the 18 B-cell subsets analyzed in this study were observed in patients that were never treated, peaked to $18 / 18$ in those on active therapy, and did not bounce back once treatment finalized (15/18).

\section{Antibody response in hematological patients and HCP}

Based on the antibody index of IgG against the RBD antigen (which is the major target for virus-neutralizing antibodies [34]), the percentage of patients that tested positive at day 7 after the second-dose vaccination was significantly inferior than that of HCP (59/83 [71\%] vs. 98/102 [96\%], respectively; $P<0.001)$. Furthermore, the antibody indexes of $\lg G$ and $\lg A$ against the RBD antigen were significantly lower in patients vs. HCP (Fig. 4A). Similar results were observed for anti-S antibody response (Supplemental Fig. 4).

Seropositivity was more frequent in patients with Hodgkin lymphoma (6/7, 86\%) and B-cell lymphoproliferative disorders (36/ $48,75 \%)$ when compared to those with monoclonal gammopathies $(17 / 28,61 \%)$ (Table 2). Seroconversion rates were greater in patients who never received treatment $(14 / 17,82 \%)$, dropped considerably in those on-therapy $(6 / 17,35 \%)$, and bounced back once patients were off-treatment (39/49, 80\%). Furthermore, antibody detection was more frequent in patients who received one $(35 / 44,80 \%)$ vs. two or more lines of therapy $(10 / 22,45 \%)$. Previous treatment with anti-CD38 monoclonal antibodies reduced to half the chances of immunogenicity $(6 / 12,50 \%)$, particularly in patients that were on active treatment. The negative impact of autologous transplant $(14 / 20,70 \%)$ and anti-CD20 therapy $(22 / 27$, $81 \%)$ in seroconversion rates was less pronounced. Patients in complete remission $(40 / 54,70 \%)$ were more frequently seropositive than those in other response categories (19/29,66\%).

Further analyses of antibody titers according to international units showed that hematological patients had significantly reduced anti-RBD IgG (median 553 vs. $6014 \mathrm{lU} / \mathrm{mL} ; P<0.001$ ) and anti-S IgG (median 912 vs. $5313 \mathrm{BAU} / \mathrm{mL} ; P<0.001$ ) compared to HCP. Median anti-RBD IgG levels were of 1262,279 , and $2634 \mathrm{IU} / \mathrm{mL}$ in patients with B-cell lymphoproliferative disorders, monoclonal gammopathies, and Hodgkin lymphoma, respectively. Thus, patients with a PC disorder had significantly lower anti-RBD IgG titers when compared to the other two disease categories (Fig. 4B). Median anti-RBD lgG levels were systematically higher in HCP vs. patients, regardless of whether the latter had never been treated or if they were on or off-therapy (3871, 133, and 719 IU/ $\mathrm{mL}$, respectively). Notwithstanding, the concentration of anti-RBD IgG was significantly lower in patients on active treatment vs. those that were off $(P=0.001)$ or had never received anti-tumor therapy $(P<0.001)$ (Fig. $4 C)$. Similar results were observed for anti$\mathrm{S}$ lgG titers (data not shown). Patients vaccinated with mRNA-1273 displayed significantly higher anti-RBD lgG levels than those vaccinated with BNT162b2 (1535.64 vs. $412.88 \mathrm{IU} / \mathrm{mL}$, respectively; $P=0.016$ ). No differences were observed in HCP (Supplemental Fig. 5). As expected, anti-RBD lgG titers significantly decreased from day 7 after second-dose to day 100 after first-dose vaccination in patients $(553-249 \mathrm{IU} / \mathrm{mL}, P<0.001)$ and $\mathrm{HCP}$ (6014-355 IU/mL, $P<0.001)$.

\section{Undocumented SARS-CoV-2 infection in hematological patients and HCP}

Seventeen of the 102 (17\%) HCP and 13/83 (16\%) patients tested positive for the $\mathrm{N}$ and Mpro virus-specific antigens, and therefore were unaware of being infected with SARS-CoV-2 before or during vaccination. As expected, anti-RBD IgG titers were significantly higher in HCP previously exposed to SARS-CoV-2 when compared to those who were not (median 14,104 vs. $4817 \mathrm{IU} / \mathrm{mL}$, respectively), and a similar kinetics was observed in patients (median 3368 vs. $458 \mathrm{IU} / \mathrm{mL}$, respectively). Interestingly, the foldchange in anti-RBD lgG levels between previously infected and non-infected patients was higher than that observed in HCP (seven- vs. threefold, respectively), without statistically significant differences in the median concentration of anti-RBD lgG after two doses of SARS-CoV-2 vaccine between previously infected patients and non-infected HCP (Fig. 4D). There were no statistical differences in the distribution of the 59 immune cell types in $\mathrm{HCP}$ with or without previous infection, and the same applied for the comparison between patients.

\section{Immunotypes associated with poor antibody response}

After observing altered immune profiles prior to vaccination, and lower seroconversion rates and reduced antibody production after vaccine administration in patients vs. $\mathrm{HCP}$, we next aimed to perform a holistic analysis of patients' demographics and disease features, treatment, and immune landscape, in relation to seroconversion and the generation of relevant concentrations of anti-RBD IgG antibodies. To this end, we stratified patients according to titer levels: lower or $>553.5 \mathrm{lU} / \mathrm{mL}$. This cutoff was selected because it represented the median concentration of antiRBD IgG found in the 83 hematological patients and because it segregated most HCP (95/102 [93\%]) from a few with clearly lower titers (Supplemental Fig. 6). Vaccine effectiveness in reducing the incidence of symptomatic and asymptomatic SARS-CoV-2 infection was reported to be $>90 \%$ in HCP [35-37]. In fact, in our cohort only $4 / 102$ (4\%) developed (mild) COVID-19 after vaccination. Thus, it can be inferred that the presence of $\geq 553.5 \mathrm{IU} / \mathrm{mL}$ antiRBD lgG confers protection to COVID-19.

The first two branches after unsupervised clustering analysis according to the relative distribution of the 59 immune cell types, divided the 83 hematological patients in 2 groups: 1 with 55 (66\%) and another, smaller and more homogeneous with 28 (34\%) patients (Fig. 5). When compared to the larger branch, the smallest was characterized by lower seroconversion rates $(8 / 28$ [29\%] vs. $45 / 55$ [82\%], $P=0.006)$ and $<553.5 \mathrm{IU} / \mathrm{mL}$ anti-RBD $\mathrm{lgG}(7 / 28$ [25\%] vs. $35 / 45$ [78\%], $P=0.002$ ). Half of the patients in the smallest branch had a B-cell lymphoproliferative disorder and the other half, a monoclonal gammopathy; by contrast, all cases with Hodgkin lymphoma clustered in the larger branch $(P=0.03)$. Patients belonging to the smaller branch were older $(P=0.007)$ and had received treatment more frequently $(P=0.002)$ including $\geq 2$ lines of therapy $(P=0.018)$. Treatment with anti-CD38 antibodies $(P=0.02)$ and immunomodulatory drugs ([IMiDs], $P=0.0099$ ) was more frequent in these patients as well. Gender, exposure to anti-CD20 or autologous transplant, the type of vaccine, and previous SARS-CoV-2 infection were not significantly associated with patients' branch.

The two branches were characterized by altered distribution of granulocytes, APC, CD4 and CD8 T cells, as well as B cells (Fig. 5 and Supplemental Fig. 7). Neutrophils and classical monocytes were significantly increased in patients belonging to the smaller branch, whereas SLAN+ non-classical monocytes were reduced. Within the T-cell compartment, the frequency of $17 / 19$ CD4 subsets and of 8/13 CD8 subsets were significantly decreased in patients belonging to the smaller branch. All 18 subsets of the B-cell compartment were markedly reduced in these cases. Overall, this holistic analysis uncovered the presence of a distinct immunotype that was significantly associated with weak 
A
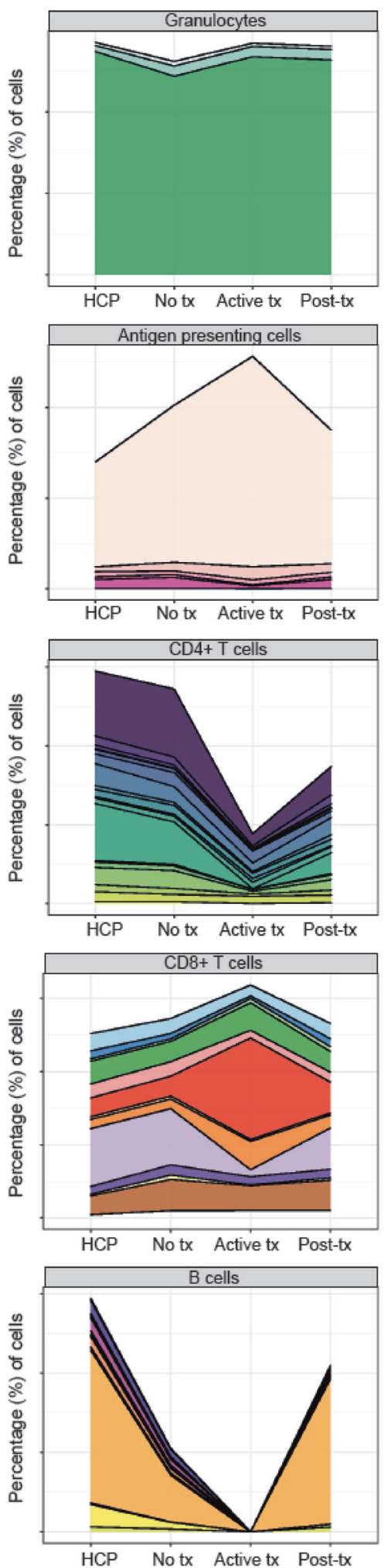

B

Basophils Eosinophils Neutrophils

Classical monocytes Intermediate monocytes

Myeloid dendritic cells

Plasmacytoid dendritic cells

SLAN- non-classical monocytes

SLAN+ non-classical monocytes

CD4+ CM CD127+ $\mathrm{CD} 4+\mathrm{CM} \mathrm{CD} 127+\mathrm{CD} 25+$

CD4+ CM CD127+ PD1+

CD4+ CM CD127low PD1+ CD4+ CMneg

CD4+ EM CD127+

CD4+ EM CD127+ CD25+ CD4+ EM CD127+ CD25+ PD1+ CD4+ EM CD127+ PD1+ CD4+ EM CD127low

CD4+ EM CD127low PD1+ CD4+ naive

CD4+ TEMRA CD127+

CD4+ TEMRA CD127low

Tfh

Tfh-like CM

Treg CM

Treg EM

Treg naive

CD8+ CM CD127+

$\mathrm{CD} 8+\mathrm{CM} \mathrm{CD} 127+\mathrm{CD} 25+$ CD8+ CM CD127low

$\mathrm{CD} 8+\mathrm{EM} \mathrm{CD} 127+$

CD8+ EM CD127+ PD1+

CD8+ EM CD127low CD8+ EM CXCR5+ CD127+ PD1+ CD8+ EM PD1+

$\mathrm{CD} 8+$ naive

CD8+ TEMRA CD127+

CD8+ TEMRA CD127+ PD1+

CD8+ TEMRA CD127low

CD8+ TEMRA PD1+

IgA+ circulating PCs IgA+ memory CD27- CD21IgA+ memory CD27- CD21+ IgA+ memory CD27+ CD21+

IgG+ IgM+ circulating PCs IgG+ memory CD27- CD21IgG+ memory $\mathrm{CD} 27-\mathrm{CD} 21+$ lgG+ memory CD27+ CD21+ IgG+ memory CD27+ CD21low IgM+ D- memory CD27- CD21IgM+ D- memory CD27- CD21+ IgM+ D- memory CD27+ CD21IgM+ D- memory CD27+ CD21+ Naive CD21Naive CD21+ IgM+ D+ CD27+ CD21 IgM+ D+ CD27+ CD21 Transitional

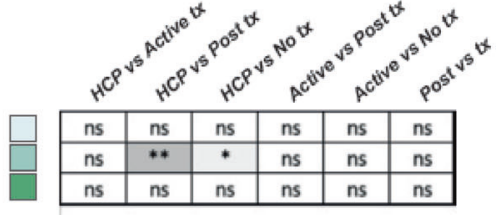

\begin{tabular}{|c|c|c|c|c|c|}
\hline$* * *$ & $* * *$ & $* * *$ & $* *$ & $*$ & ns \\
\hline$*$ & $* * *$ & $*$ & ns & ns & ns \\
\hline ns & ns & ns & ns & ns & ns \\
\hline$*$ & ns & ns & ns & ns & ns \\
\hline ns & ns & ns & ns & ns & ns \\
\hline ns & ns & ns & ns & ns & ns \\
\hline
\end{tabular}

\begin{tabular}{|c|c|c|c|c|c|}
\hline$* * *$ & $* *$ & ns & $* *$ & $* *$ & $* *$ \\
\hline$* *$ & ns & ns & $*$ & $*$ & ns \\
\hline$* *$ & ns & ns & $* *$ & $*$ & ns \\
\hline$* *$ & $*$ & ns & $* *$ & ns & ns \\
\hline$* * *$ & $* * *$ & ns & $*$ & $* *$ & $*$ \\
\hline ns & ns & ns & ns & ns & ns \\
\hline$* * *$ & $* *$ & $*$ & ns & ns & ns \\
\hline$* *$ & ns & ns & $*$ & ns & ns \\
\hline ns & ns & ns & ns & ns & ns \\
\hline ns & ns & ns & ns & ns & ns \\
\hline ns & ns & ns & ns & ns & ns \\
\hline$* * *$ & $* * *$ & ns & $* * *$ & $* * *$ & $* *$ \\
\hline ns & ns & ns & ns & ns & ns \\
\hline ns & ns & ns & ns & ns & ns \\
\hline$* * *$ & ns & ns & $* *$ & $*$ & ns \\
\hline$* * *$ & $* * *$ & ns & $* * *$ & $* * *$ & $*$ \\
\hline$* * *$ & $* * *$ & ns & $*$ & $*$ & ns \\
\hline$* *$ & $\cdots * *$ & $*$ & ns & ns & ns \\
\hline$* * *$ & $* * *$ & ns & $* * *$ & $* * *$ & $*$ \\
\hline
\end{tabular}

\begin{tabular}{|c|c|c|c|c|c|}
\hline$* *$ & ns & ns & $*$ & ns & ns \\
\hline$*$ & ns & $*$ & ns & ns & $*$ \\
\hline ns & $* * *$ & ns & ns & ns & ns \\
\hline ns & ns & ns & ns & ns & ns \\
\hline$* *$ & ns & ns & ns & ns & ns \\
\hline$* *$ & $* *$ & ns & ns & $*$ & ns \\
\hline ns & ns & ns & ns & ns & ns \\
\hline$*$ & $*$ & ns & ns & ns & ns \\
\hline$* * *$ & $* *$ & ns & $* *$ & $* * *$ & $*$ \\
\hline ns & ns & ns & ns & ns & ns \\
\hline$*$ & $*$ & ns & $*$ & $*$ & ns \\
\hline ns & ns & ns & ns & ns & ns \\
\hline ns & $*$ & ns & ns & ns & ns \\
\hline
\end{tabular}

\begin{tabular}{|c|c|c|c|c|c|}
\hline$* * *$ & $* *$ & $* * *$ & $* *$ & $* *$ & $\mathrm{~ns}$ \\
\hline$* * *$ & $* * *$ & $*$ & $* * *$ & $* * *$ & $*$ \\
\hline$* * *$ & $*$ & $\mathrm{~ns}$ & $* * *$ & $* * *$ & $\mathrm{~ns}$ \\
\hline$* * *$ & $* * *$ & $*$ & $* * *$ & $* * *$ & $*$ \\
\hline$* * *$ & $* * *$ & $* * *$ & $* *$ & $*$ & $\mathrm{~ns}$ \\
\hline$* * *$ & $*$ & $\mathrm{~ns}$ & $* *$ & $* *$ & $\mathrm{~ns}$ \\
\hline$* * *$ & $* *$ & $* *$ & $* * *$ & $* * *$ & $\mathrm{~ns}$ \\
\hline$* * *$ & $* * *$ & $* * *$ & $* * *$ & $* * *$ & $\mathrm{~ns}$ \\
\hline$* * *$ & $* * *$ & $* *$ & $* * *$ & $* * *$ & $\mathrm{~ns}$ \\
\hline$* * *$ & $\mathrm{~ns}$ & $\mathrm{~ns}$ & $* *$ & $* *$ & $\mathrm{~ns}$ \\
\hline$* * *$ & $* * *$ & $\mathrm{~ns}$ & $* * *$ & $* * *$ & $\mathrm{~ns}$ \\
\hline$* * *$ & $* * *$ & $* * *$ & $* * *$ & $* * *$ & $*$ \\
\hline$* * *$ & $* * *$ & $* * *$ & $* * *$ & $* * *$ & $* *$ \\
\hline$* * *$ & $* *$ & $*$ & $* *$ & $*$ & $\mathrm{~ns}$ \\
\hline$* * *$ & $\mathrm{~ns}$ & $* * *$ & $* * *$ & $*$ & $*$ \\
\hline$* * *$ & $* * *$ & $* * *$ & $* * *$ & $* * *$ & $\mathrm{~ns}$ \\
\hline$* * *$ & $* * *$ & $* * *$ & $* * *$ & $* * *$ & $\mathrm{~ns}$ \\
\hline$* * *$ & $\mathrm{~ns}$ & $*$ & $*$ & $*$ & $\mathrm{~ns}$ \\
\hline
\end{tabular}

Fig. 3 Tumor-related immune dysregulation and therapy-related immunosuppression. A Relative distribution of granulocytes, antigenpresenting cells (APC), CD4 and CD8 T cells, and B cells across health care practitioners (HCPs), hematological patients that had never received treatment (No tx, N=17), those that were on (Active tx, $N=17$ ), and patients that were off-treatment (Post-tx, $N=49)$ before vaccination. B Statistical significance of differences across groups (with graphical representation of such differences in Supplemental Fig. 3). APC, antigenpresenting cells; CM, central memory; EM, effector memory; Treg, T regulatory cells; Tfh, T follicular-like; TEMRA, terminally effector memory CD45RA+; PC, plasma cells. ${ }^{*} P<0.05 ;{ }^{* *} P<0.01 ;{ }^{* *} P<0.001$; n.s., not significant. 
A

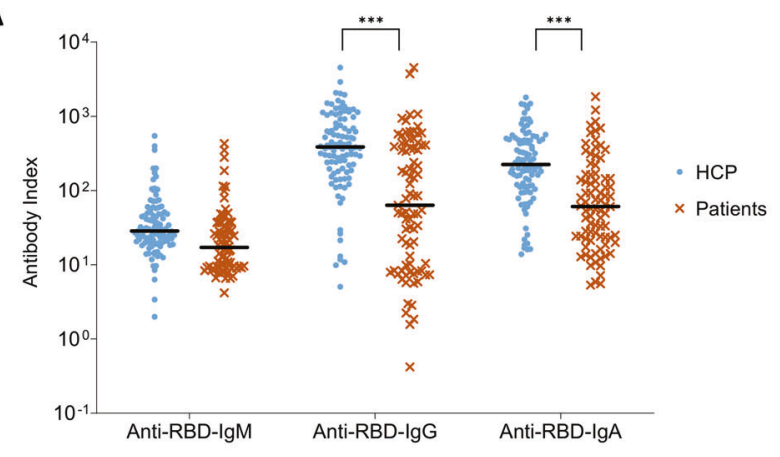

B

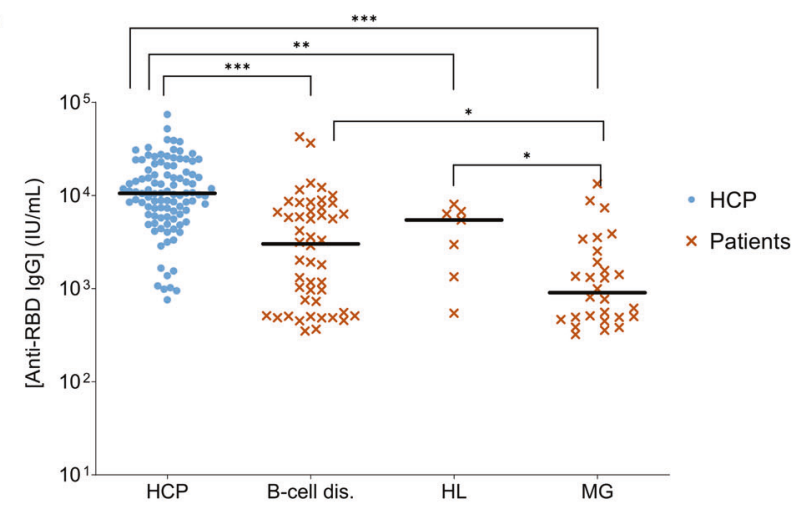

C

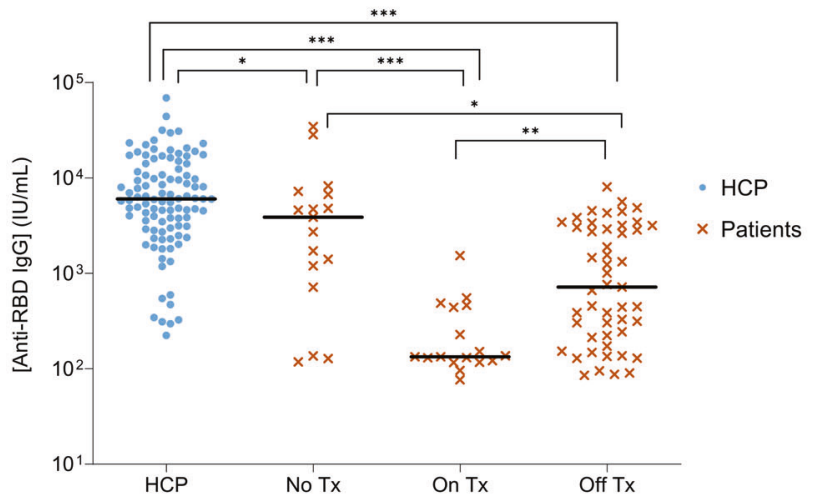

D

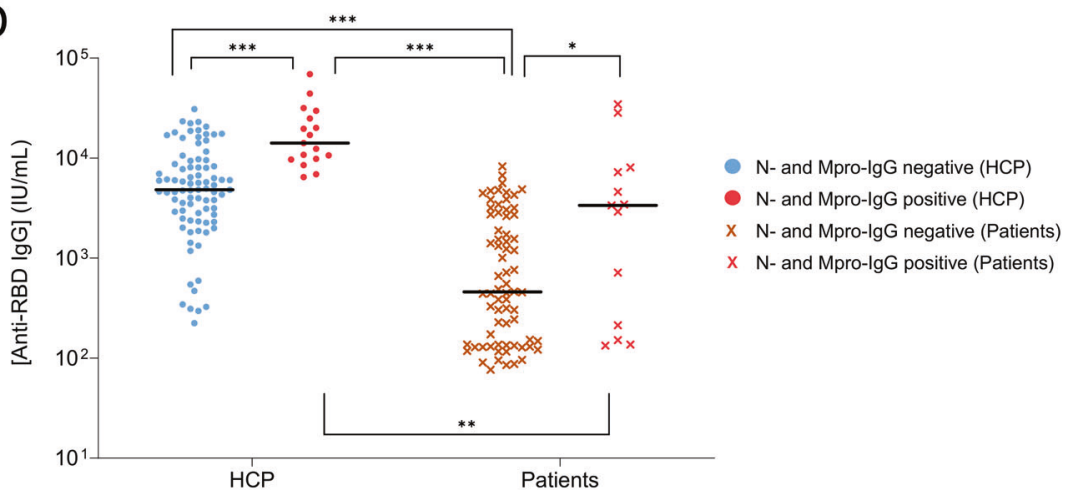

Fig. 4 Antibody response in hematological patients and HCP. A Index of $\lg M$, IgG, and IgA antibodies against the receptor-binding domain (RBD) of the S-glycoprotein in health care practitioners $(\mathrm{HCP}, N=102)$ and hematological patients $(N=83)$. B Concentration of anti-RBD lgG in $\mathrm{HCP}$, hematological patients with B-cell lymphoproliferative disorders (B-cell dis., $N=48$ ), monoclonal gammopathies (MG, $N=28$ ) and Hodgkin lymphoma (HL, $N=7)$. C Concentration of anti-RBD lgG in HCP, hematological patients that had never received treatment (No Tx, $N=17)$, those that were on $(N=17)$, and patients that were off-treatment $(N=49)$ before vaccination. $D$ Concentration of anti-RBD IgG in HCP and hematological patients with or without previous SARS-CoV-2 infection, based on the detection of IgG antibodies against the nucleocapsid (N) protein and the main virus protease (Mpro). Among HCP, 85 were negative and 17 positive for both antigens. Among hematological patients, 70 were negative and 13 positive for both antigens. In all panels, horizontal lines represent the median. ${ }^{*} P<0.05 ;{ }^{*} P<0.01 ;{ }^{* * *} P<0.001$. 


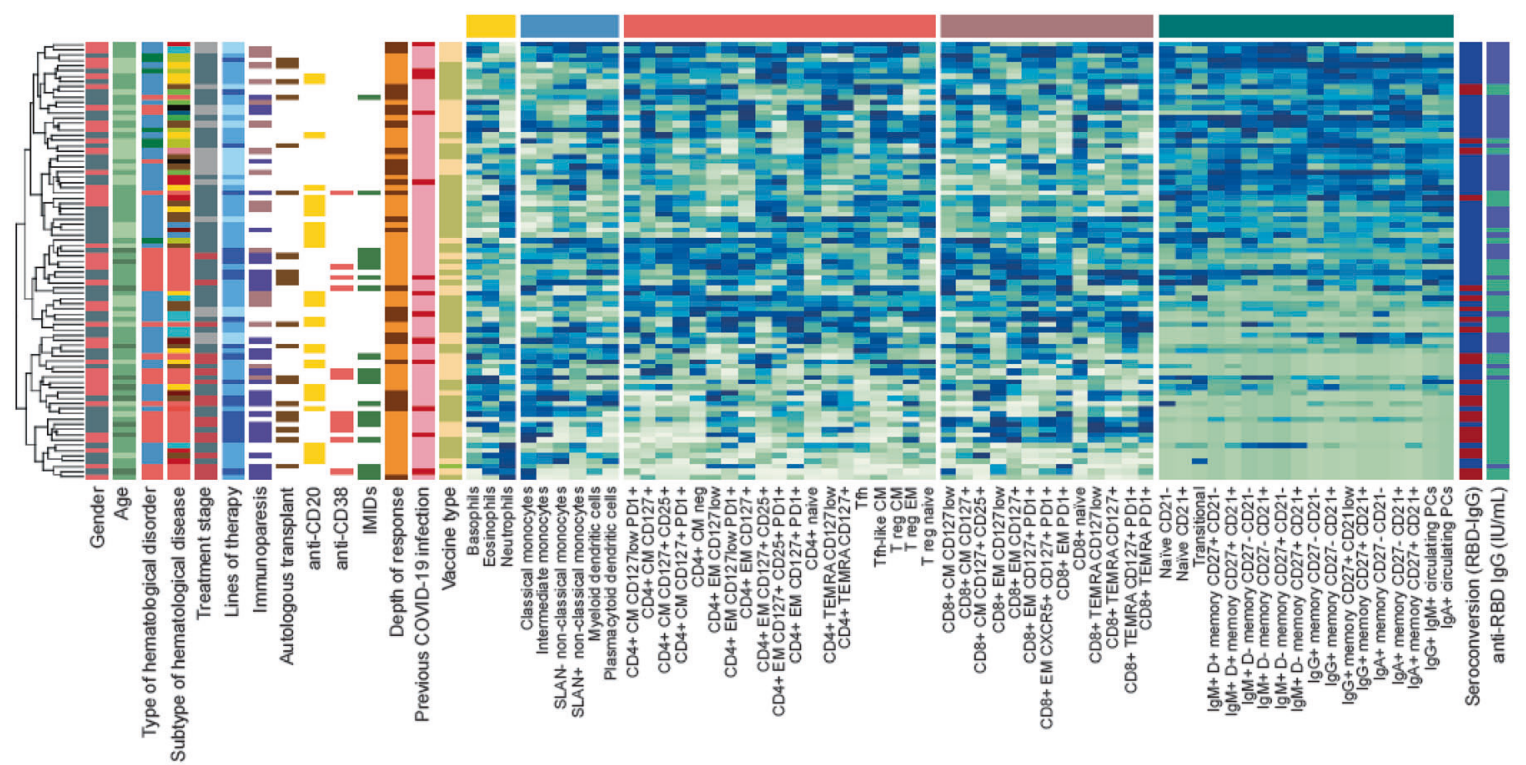

Immune cell compartment
Granulocytes
Antigen presenting cells
CD4+T cells
CD $8+T$ cells
B cells
Gender
Female
Male
Age
$<50$
$50-70$
$>70$
Type of hematological disorder
B-cell lymphoproliferative disorder
Hodgkin lymphoma
Monoclonal gammopathy
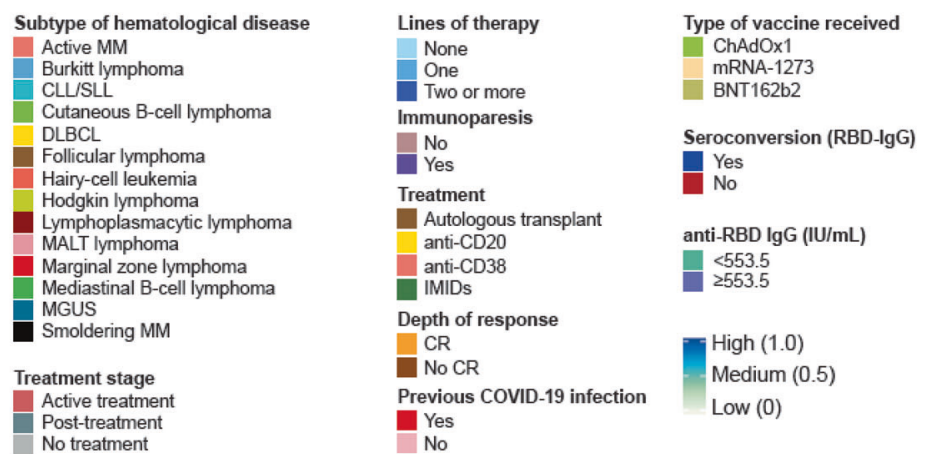

Fig. 5 Immunotypes associated with poor antibody response. Unsupervised clustering of 83 hematological patients and 102 health care practitioners (HCPs) based on the relative percentile distribution of 59 immune cell types in peripheral blood before vaccination, categorized into four groups: granulocytes, antigen-presenting cell (APC) subsets, T-cell and B-cell subsets. For the columns to the left of the cellpercentage data, moving from left to right, rows are color-coded according to gender, age groups, type and subtype of hematological malignancy, treatment status, number of previous lines of therapy, immunoparesis, autologous transplant, treatment with anti-CD20 antibodies, anti-CD38 antibodies and immunomodulatory drugs (IMiDs), depth of response to treatment (complete remission, CR), previous SARS-CoV-2 infection, and vaccine type. For the columns to the right of the cell-percentage data, moving from left to right, rows are colorcoded according to seroconversion and presence of $\geq 553.5 \mathrm{IU} / \mathrm{mL}$ lgG against the receptor-binding domain (RBD) of the S-glycoprotein. $\mathrm{CM}$, central memory; EM, effector memory; Treg, T regulatory cells; Tfh, T follicular-like; TEMRA, terminally effector memory CD45RA+; PC, plasma cells.

immunogenicity, as well as patients' age, disease category, treatment status, and previous exposure to anti-CD38 antibodies and IMiDs. As these two agents were frequently administered in the same patients, either simultaneously or in different lines, the isolated effect of each drug cannot be determined.

\section{Immune biomarkers of immunogenicity}

Optimal cutoffs for association with the generation of relevant concentrations of anti-RBD lgG antibodies were determined for percentages of each of the 59 immune cell types based on their AUC (Supplemental Table 3). Using these cutoffs, the frequencies of 43 immune cell types were significantly associated with less or $>553.5 \mathrm{lU} / \mathrm{mL}$ anti-RBD $\mathrm{lgG}$. Lasso regression was subsequently performed for feature selection, and six immune cell types were selected by the algorithm for logistic regression multivariate analysis: neutrophils, classical monocytes, CD4 and CD8 effector memory CD127low $T$ cells, as well as naive CD21+ and IgM+D+ memory B cells. Clinical parameters significantly associated with < or $>553.5 \mathrm{IU} / \mathrm{mL}$ anti-RBD lgG were the diagnosis of a monoclonal gammopathy $(P=0.03)$, treatment status $(P<0.001)$, number of prior lines of therapy $(P=0.003)$, and anti-CD38 therapy $(P=0.03)$. Diagnosis of a monoclonal gammopathy decreased the model's accuracy and was therefore excluded from the logistic regression. Other patient-related or disease-related characteristics, including age and treatment with IMiDs, were not significantly associated.

On logistic regression multivariate analysis, the six immune cell types and two clinical parameters showed independent predictive value (Fig. 6A). Whereas no prior therapy and increased frequencies of both $\mathrm{B}$-cell subsets were associated with $>553.5 \mathrm{lU} / \mathrm{mL}$ anti-RBD lgG, prior exposure to anti-CD38 therapy, and the expansion of neutrophils, classical monocytes, and the two T-cell subsets, were associated with lower antibody titers (Fig. $6 \mathrm{~A}, \mathrm{~B}$ ). The AUC of the logistic regression model was 0.90 (Fig. 6C), with only partial correlation between immune and clinical covariates (Fig. 6D). Any attempt to simplify the model by removing one or more of the parameters described above, significantly impaired its accuracy (data not shown). Crossvalidation scores for four folds of the data generated AUC of $0.89,0.80,0.88$, and 0.95 , suggesting that the model may yield accurate predictions to new unseen data (Fig. 6E). Thus, these 

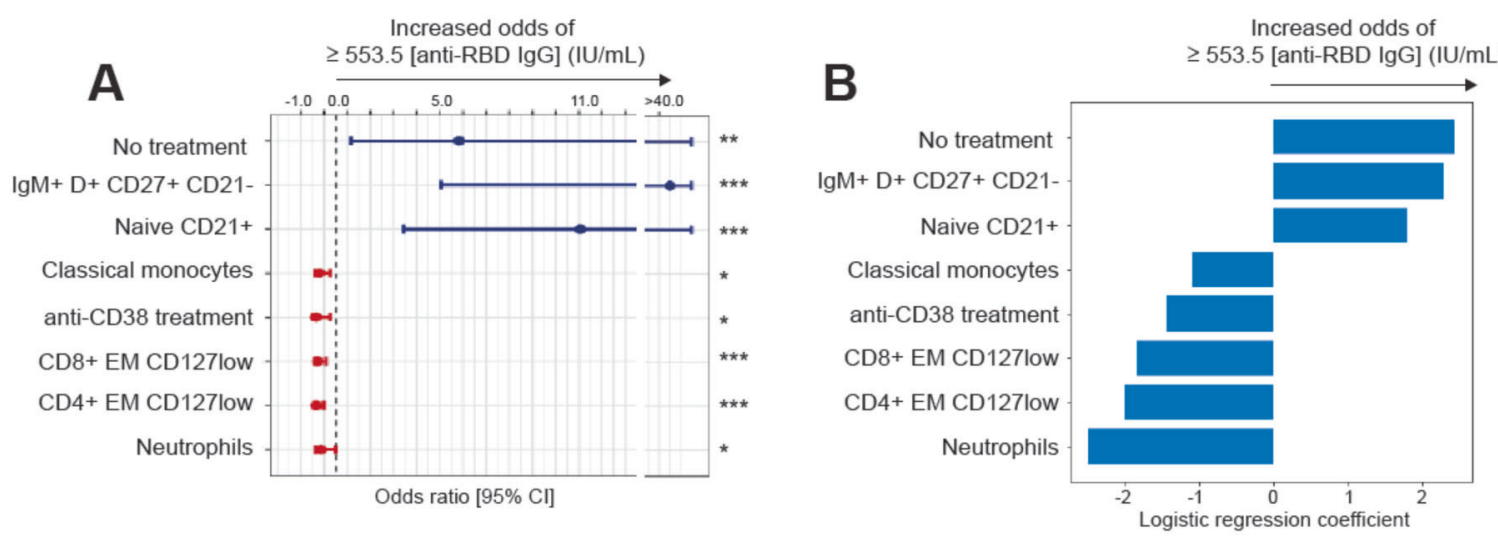

C
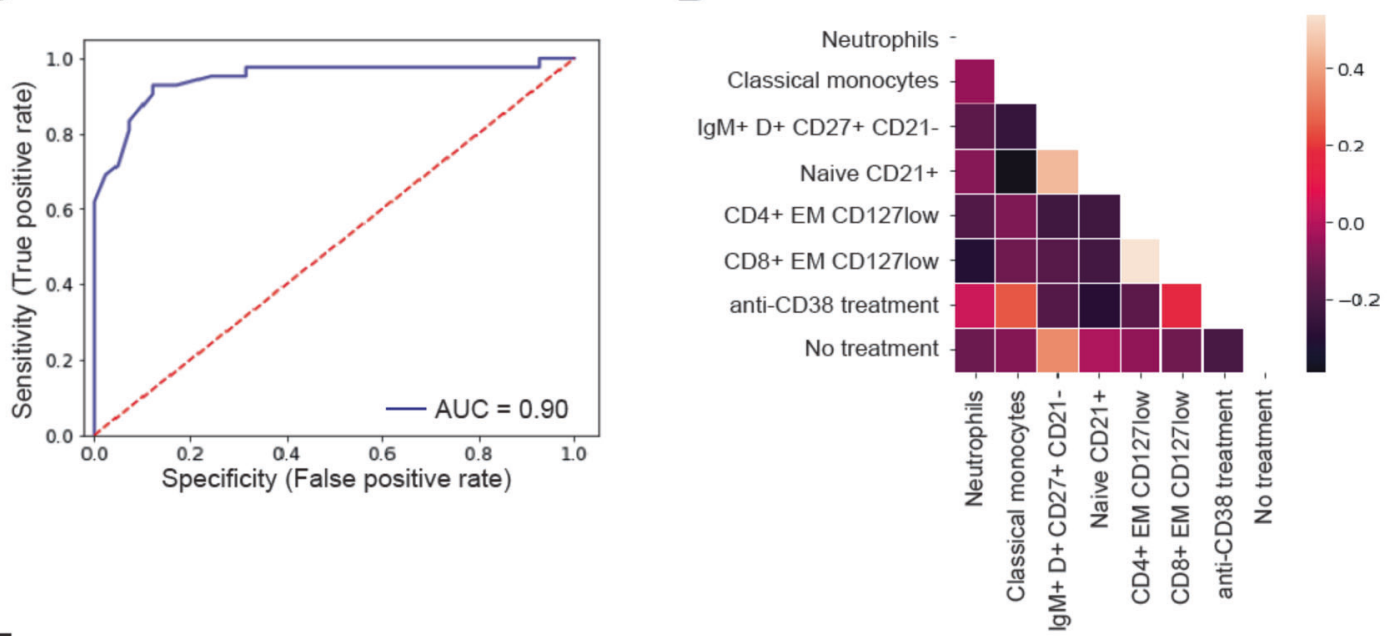

E

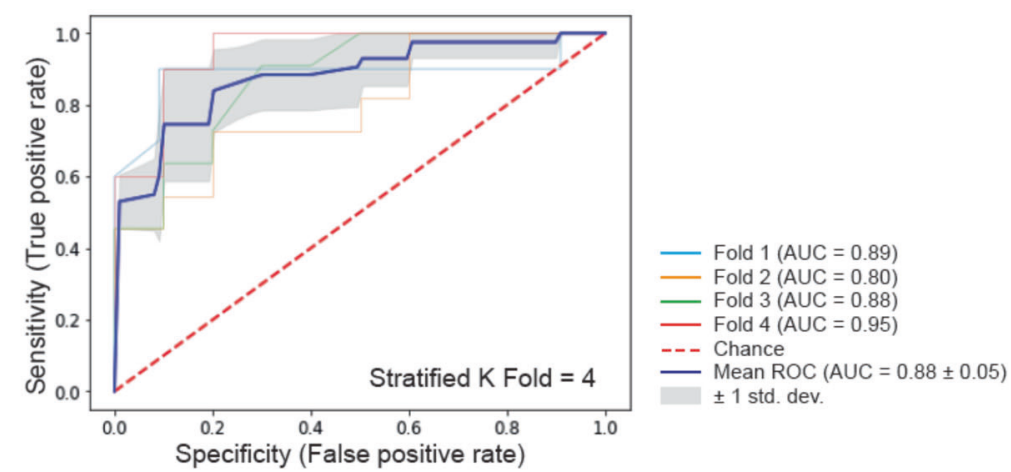

Fig. 6 Immune biomarkers of immunogenicity. A Odds ratio univariate analysis with $95 \%$ confidence intervals (Cl) of variables included in the logistic regression model. B Logistic regression coefficients with treatment-related features as well as immune biomarkers associated with generation of $\geq 553.5 \mathrm{lU} / \mathrm{mL}$ of lgG antibodies against the receptor-binding domain (RBD) of the S-glycoprotein. C Area under the curve (AUC) of prediction probabilities of patients' dataset. D Correlation matrix of immune and treatment-related features. E Fourfold cross-validation of AUC of prediction probabilities of patients' dataset.

results identify six immune biomarkers predictive of weak immunogenicity, which are independent of patient' demographics and clinical characteristics.

\section{DISCUSSION}

The dismal prognosis of COVID-19 in patients with hematological malignancies is well established [38]. There is emerging evidence, suggesting reduced SARS-CoV-2 vaccine effectiveness in these patients [18, 19, 28-30, 39, 20-27]. However, to our knowledge, there is no data on the immune landscape of hematological patients prior vaccination, nor if it can help decipher the mechanism underlying the lack of response (particularly in unexpected cases) and, ultimately, predict seroconversion. Here we performed a comprehensive immunological characterization of hematological patients prior to vaccination, which shows marked differences when compared to HCP of similar age. These analyses also exposed the extent of immunosuppression induced by anticancer treatment and uncovered that immune dysregulation is present before and persists after therapy. Our results 
translated into cutoffs for broad use of new immune biomarkers to predict antibody response after vaccine for COVID-19 in hematological patients.

As expected, most of the significant differences in the immune landscape of this cohort of patients were observed in the B-cell compartment. More importantly, the marked reduction in the frequency of numerous B-cell subsets observed in patients with B-cell lymphoproliferative disorders, monoclonal gammopathies, and to less extent, Hodgkin lymphoma, translated into lower antiRBD and anti-S immunoglobulin levels after second-dose SARSCoV-2 vaccination. Furthermore, due to the multiplex nature of the serological flow cytometry assay used in this study, we unveiled that hematological patients had reduced indexes of both IgG and $\lg \mathrm{A}$ antibodies. Although the roles of $\lg \mathrm{A}$ and mucosal immunity in COVID-19 protection remain unknown [40], IgA antibodies are generally considered as the most important immunoglobulin to neutralize infectious pathogens in the respiratory tract.

Seropositivity remains an imperfect proxy for clinically protective immunity against SARS-CoV-2 [41]. Here we reported rates of seroconversion and IgG levels against the RBD fragment of the Spike glycoprotein, which is the major target of neutralizing antibodies. We established a cutoff of $553.5 \mathrm{IU} / \mathrm{mL}$, because it was the median value found in patients and it clearly segregated a few $\mathrm{HCP}$ with antibody titers below the cutoff from the remaining control group. Of note, only four HCP developed (mild) COVID-19 after vaccination, which reinforces that the levels of antibody production above this concentration are clinically meaningful to prevent symptomatic infection. Although it was outside the scope of our study, the simultaneous analysis of seroconversion rates and antibody concentration yielded interesting observations. First, vaccination with mRNA-1273 yielded significantly higher anti-RBD IgG titers in hematological patients than BNT162b2, as described elsewhere [42]. Second, although patients with Hodgkin lymphoma may generally produce antibodies, their titers were lower than those of HCP. Third, seroconversion rates between patients with a mature B-cell and PC neoplasm were not considerably different, but immunogenicity was significantly weaker in those with monoclonal gammopathies. Fourth, although seroconversion rates were similar between patients that never received anticancer therapy and those that were off-treatment, antibody production was impaired in the latter. Thus, ongoing and future analysis should focus on antibody concentration beyond seroconversion rates and use if possible, assays that are calibrated against the WHO Standard for cross-study comparison.

Using anti-RBD and anti-S immunoglobulin assays as a surrogate for COVID-19 immunity in lieu of neutralizing antibodies against SARS-CoV-2 is controversial. However, it is reasonable to consider that anti-RBD and anti-S titers would be highly correlated with neutralizing antibody activity [15], and such a correlation was recently shown in a cohort of hematological patients [39]. Another limitation of this study is that antibody titers do not fully account for protection against COVID-19 compared to other forms of immunity such as SARS-CoV-2-specific memory T cells, which may be protective even in seronegative patients. Noteworthy, a reduced T-cell response compared to healthy individuals and patients with solid cancer, has been detected in those with hematological malignancies after SARS-CoV-2 vaccination $[43,44]$. Although measuring T-cell specificity was outside the scope of this study, we showed that, when compared to HCP of similar age, the T-cell compartment was significantly altered in hematological patients, particularly those with a monoclonal gammopathy, and in those on or off-treatment. Interestingly, we observed in these patients a pronounced reduction of Tfh cell types, which play an essential role in regulating the germinal center reaction and, consequently, the generation of high-affinity antibodies $[45,46]$. Thus, our results may shed some light on the low rate of T-cell responses in hematological patients [39, 44], particularly in seronegative cases [44].
In $\mathrm{MM}$, a positive correlation between serological response and CD19+ or CD4+ lymphocyte counts was most recently observed, while CD8+ T-cell counts were negatively correlated [47]. In another study that included a more heterogeneous population of patients with hematological malignancies, the strong correlation between CD19+ B cells and serological response was confirmed, and there was no correlation between antibody concentration and CD4+ or CD8 + T cells [39]. Of note, CD19+ B-cell counts had independent predictive value in the MM cohort and in the larger series of patients with hematological malignancies [39, 47]. Here we uncovered the presence of a distinct immunotype that, although significantly associated with some disease and treatment-related features, identified patients with a B-cell and a PC neoplasm with more frequent seronegativity and lower antibody titers after second-dose vaccination. More importantly, our results show that $\mathrm{CD} 4+, \mathrm{CD} 8+$, and CD19+ lymphocytes, and many of their respective subsets are essential for vaccine effectiveness and should be monitored to predict immunogenicity. Increased numbers of neutrophils and classical monocytes were significantly associated with poor antibody response, and this could be related to their immunosuppressive phenotype [48].

The influence of anticancer treatment and timing of the immune response to SARS-CoV-2 remains a topic of clinical interest and controversy. Thus, and until more definitive data emerges, decisions around delivery or interruption of anticancer therapy should be based on individual risk-benefit assessment incorporating factors including cancer prognosis and patient comorbidities. Here we aimed to provide new biomarkers to help on such decisions and thus, we identified six immune cell types that depict patients' immune landscape (i.e., percentages of immunosuppressive cells and of T- and B-cell subsets representative of the cellular and humoral immunity) and are independent of other disease features in order to predict immunogenicity prior to vaccination. Despite the complex phenotype of some immune cell types, which is the result of the holistic and computational flow cytometry analysis we performed, there are standardized methods for their quantification [49]. Immune profiling prior vaccination for COVID-19 could be particularly informative in patients that are off active treatment, who are expected to become seropositive but may have poor antibody response due to tumor-related immune dysregulation and may benefit from third-dose vaccination.

Interestingly, we found that hematological patients with undocumented SARS-CoV-2 infection developed median antibody titers after two doses that were similar to those found in HCP. Thus, our data reproduces previous findings in non-cancer patients $[50,51]$ and could suggest that a third challenge to SARS-CoV-2 antigens can improve immunogenicity. Just recently, the US Food and Drugs Administration amended the emergency use authorization for the BNT162b2 and mRNA-1273 COVID-19 vaccines to allow for an additional dose for certain people with compromised immune systems. That group includes, specifically, individuals over 65 years old, solid organ transplant recipients, or those who are diagnosed with conditions that are considered to be equally immunocompromised. Our study exposes the depth of immune dysregulation in patients with hematological malignancies and urges reflection on whether immune profiling before boosting is warranted to identify optimal timing of third-dose vaccination.

\section{REFERENCES}

1. Kuderer NM, Choueiri TK, Shah DP, Shyr Y, Rubinstein SM, Rivera DR, et al. Clinical impact of COVID-19 on patients with cancer (CCC19): a cohort study. Lancet. 2020;395:1907-18. https://pubmed.ncbi.nlm.nih.gov/32473681/

2. Wang QQ, Berger NA, Xu R. Analyses of risk, racial disparity, and outcomes among US patients with cancer and COVID-19 infection. JAMA Oncol. 2021;7:220-7. https://pubmed.ncbi.nlm.nih.gov/33300956/

3. Mehta V, Goel S, Kabarriti R, Cole D, Goldfinger M, Acuna-Villaorduna A, et al. Case fatality rate of cancer patients with COVID-19 in a New York Hospital system. Cancer Discov. 2020;10:935-41. https://pubmed.ncbi.nlm.nih.gov/32357994/ 
4. Robilotti EV, Babady NE, Mead PA, Rolling T, Perez-Johnston R, Bernardes M, et al. Determinants of COVID-19 disease severity in patients with cancer. Nat Med. 2020;26:1218-23. https://pubmed.ncbi.nlm.nih.gov/32581323/

5. Bange EM, Han NA, Wileyto P, Kim JY, Gouma S, Robinson J, et al. CD8+ T cells contribute to survival in patients with COVID-19 and hematologic cancer. Nat Med. 2021;27:1280-9. https://pubmed.ncbi.nlm.nih.gov/34017137/

6. Grivas P, Khaki AR, Wise-Draper TM, French B, Hennessy C, Hsu CY, et al. Association of clinical factors and recent anticancer therapy with COVID-19 severity among patients with cancer: a report from the COVID-19 and Cancer Consortium. Ann Oncol. 2021;32:787-800. https://pubmed.ncbi.nlm.nih.gov/33746047/

7. Maia C, Martín-Sánchez E, Garcés JJ, de Cerio ALD, Inogés S, Landecho MF, et al. Immunologic characterization of COVID-19 patients with hematological cancer. Haematologica. 2021;106:1457-60. https://pubmed.ncbi.nlm.nih.gov/33327714/

8. Martín-Sánchez E, Garcés JJ, Maia C, Inogés S, López-Díaz de Cerio A, CarmonaTorre F, et al. Immunological biomarkers of fatal COVID-19: a study of 868 patients. Front Immunol. 2021;12. https://pubmed.ncbi.nlm.nih.gov/34012444/

9. Griffiths EA, Segal BH. Immune responses to COVID-19 vaccines in patients with cancer: promising results and a note of caution. Cancer Cell. 2021;39. https:// pubmed.ncbi.nlm.nih.gov/34242573/

10. Abdul-Jawad S, Baù L, Alaguthurai T, del Molino del Barrio I, Laing AG, Hayday TS, et al. Acute immune signatures and their legacies in severe acute respiratory syndrome coronavirus-2 infected cancer patients. Cancer Cell. 2021;39:257-.e6. https://pubmed.ncbi.nlm.nih.gov/33476581/

11. Passamonti F, Cattaneo C, Arcaini L, Bruna R, Cavo M, Merli F, et al. Clinical characteristics and risk factors associated with COVID-19 severity in patients with haematological malignancies in Italy: a retrospective, multicentre, cohort study. Lancet Haematol. 2020;7:e737-45. https://pubmed.ncbi.nlm.nih.gov/32798473/

12. Mato AR, Roeker LE, Lamanna N, Allan JN, Leslie L, Pagel JM, et al. Outcomes of COVID-19 in patients with CLL: a multicenter international experience. Blood. 2020;136:1134-43. https://pubmed.ncbi.nlm.nih.gov/32688395/

13. Chari A, Samur MK, Martinez-Lopez J, Cook G, Biran N, Yong K, et al. Clinical features associated with COVID-19 outcome in multiple myeloma: First results from the International Myeloma Society data set. Blood. 2020;136:3033-40. https://pubmed.ncbi.nlm.nih.gov/33367546/

14. Marra A, Generali D, Zagami P, Cervoni V, Gandini S, Venturini S, et al. Seroconversion in patients with cancer and oncology health care workers infected by SARS-CoV-2. Ann Oncol. 2021;32:113-9. https://pubmed.ncbi.nlm.nih.gov/ 33098994/

15. Addeo A, Shah PK, Bordry N, Hudson RD, Albracht B, Di Marco M, et al. Immunogenicity of SARS-CoV-2 messenger RNA vaccines in patients with cancer. Cancer Cell. 2021;39:1091-.e2. https://pubmed.ncbi.nlm.nih.gov/34214473/

16. Thakkar A, Gonzalez-Lugo JD, Goradia N, Gali R, Shapiro LC, Pradhan K, et al. Seroconversion rates following COVID-19 vaccination among patients with cancer. Cancer Cell. 2021;39:1081-.e2. https://pubmed.ncbi.nlm.nih.gov/34133951/

17. Agha M, Blake M, Chilleo C, Wells A, Haidar G. Suboptimal response to COVID-19 mRNA vaccines in hematologic malignancies patients. Serv Heal Sci. 2021. http:// www.ncbi.nlm.nih.gov/pubmed/33851182\%0A http://www.pubmedcentral.nih. gov/articlerender.fcgi?artid $=$ PMC8043479

18. Greenberger LM, Saltzman LA, Senefeld JW, Johnson PW, DeGennaro LJ, Nichols GL. Antibody response to SARS-CoV-2 vaccines in patients with hematologic malignancies. Cancer Cell. 2021;39:1031-3. https://pubmed.ncbi.nlm.nih.gov/ 34331856/

19. Passamonti F, Romano A, Salvini M, Merli F, Porta MGD, Bruna R, et al. COVID-19 elicits an impaired antibody response against SARS-CoV-2 in patients with haematological malignancies. Br J Haematol. 2021. https://pubmed.ncbi.nlm.nih.gov/ 34272724/

20. Herishanu $Y$, Avivi I, Aharon A, Shefer G, Levi S, Bronstein $Y$, et al. Efficacy of the BNT162b2 mRNA COVID-19 vaccine in patients with chronic lymphocytic leukemia. Blood. 2021;137:3165-73. https://pubmed.ncbi.nlm.nih.gov/33861303/

21. Parry H, Mcllroy G, Bruton R, Ali M, Stephens C, Damery S, et al. Antibody responses after first and second Covid-19 vaccination in patients with chronic lymphocytic leukaemia. Blood Cancer J. 2021;11:136. https://pubmed.ncbi.nlm. nih.gov/34330895/

22. Ghione P, Gu JJ, Attwood K, Torka P, Goel S, Sundaram S, et al. Impaired humoral responses to COVID-19 vaccination in patients with lymphoma receiving Bcell-directed therapies. Blood. 2021;138:811-4. https://pubmed.ncbi.nlm.nih.gov/ 34189565/

23. Lim SH, Campbell N, Johnson M, Joseph-Pietras D, Collins GP, O'Callaghan A, et al. Antibody responses after SARS-CoV-2 vaccination in patients with lymphoma. Lancet Haematol. 2021;8:e542-4. https://pubmed.ncbi.nlm.nih.gov/34224667/

24. Terpos E, Trougakos IP, Gavriatopoulou M, Papassotiriou I, Sklirou AD, NtanasisStathopoulos I, et al. Low neutralizing antibody responses against SARS-CoV-2 in older patients with myeloma after the first BNT162b2 vaccine dose. Blood. 2021;137:3674-6. https://pubmed.ncbi.nlm.nih.gov/33861315/
25. Terpos E, Gavriatopoulou M, Ntanasis-Stathopoulos I, Briasoulis A, Gumeni S, Malandrakis $P$, et al. The neutralizing antibody response post COVID-19 vaccination in patients with myeloma is highly dependent on the type of antimyeloma treatment. Blood Cancer J. 2021;11. https://pubmed.ncbi.nlm.nih.gov/ 34341335/

26. Stampfer SD, Goldwater MS, Jew S, Bujarski S, Regidor B, Daniely D, et al. Response to mRNA vaccination for COVID-19 among patients with multiple myeloma. Leukemia. 2021. https://pubmed.ncbi.nlm.nih.gov/34326466/

27. Avivi I, Balaban R, Shragai T, Sheffer G, Morales M, Aharon A, et al. Humoral response rate and predictors of response to BNT162b2 mRNA COVID19 vaccine in patients with multiple myeloma. Br J Haematol. 2021. https://pubmed.ncbi.nlm. nih.gov/34196388/

28. Van Oekelen O, Gleason CR, Agte S, Srivastava K, Beach KF, Aleman A, et al. Highly variable SARS-CoV-2 spike antibody responses to two doses of COVID-19 RNA vaccination in patients with multiple myeloma. Cancer Cell. 2021;39:1028-30. https://pubmed.ncbi.nlm.nih.gov/34242572/

29. Pimpinelli F, Marchesi F, Piaggio G, Giannarelli D, Papa E, Falcucci $P$, et al. Fifthweek immunogenicity and safety of anti-SARS-CoV-2 BNT162b2 vaccine in patients with multiple myeloma and myeloproliferative malignancies on active treatment: preliminary data from a single institution. J Hematol Oncol. 2021;14. https://pubmed.ncbi.nlm.nih.gov/34001183/

30. Bird S, Panopoulou A, Shea RL, Tsui M, Saso R, Sud A, et al. Response to first vaccination against SARS-CoV-2 in patients with multiple myeloma. Lancet Haematol. 2021;8:e389-92. https://pubmed.ncbi.nlm.nih.gov/33887255/

31. Cáceres-Martell Y, Fernández-Soto D, Campos-Silva C, García-Cuesta EM, Casasnovas JM, Navas-Herrera $D$, et al. Single-reaction multi-antigen serological test for comprehensive evaluation of SARS-CoV-2 patients by flow cytometry. Eur J Immunol. 2021. https://pubmed.ncbi.nlm.nih.gov/34358329/

32. Kalina T, Flores-Montero J, Van Der Velden VHJ, Martin-Ayuso M, Böttcher S, Ritgen $M$, et al. EuroFlow standardization of flow cytometer instrument settings and immunophenotyping protocols. Leukemia. 2012;26:1986-2010. https:// pubmed.ncbi.nlm.nih.gov/22948490/

33. Botta C, Maia C, Garcés J, Termini R, Perez C, Manrique I, et al. FlowCT for the analysis of large immunophenotypic datasets and biomarker discovery in cancer immunology. Blood Adv. 2021. https://pubmed.ncbi.nlm.nih.gov/34587246/

34. Azkur AK, Akdis M, Azkur D, Sokolowska M, van de Veen W, Brüggen MC, et al. Immune response to SARS-CoV-2 and mechanisms of immunopathological changes in COVID-19. Allergy Eur J Allergy Clin Immunol. 2020;75:1564-81. https://pubmed.ncbi.nlm.nih.gov/32396996/

35. Hall VJ, Foulkes S, Saei A, Andrews N, Oguti B, Charlett A, et al. COVID-19 vaccine coverage in health-care workers in England and effectiveness of BNT162b2 mRNA vaccine against infection (SIREN): a prospective, multicentre, cohort study. Lancet. 2021;397:1725-35. https://pubmed.ncbi.nlm.nih.gov/33901423/

36. Angel $Y$, Spitzer A, Henig O, Saiag E, Sprecher E, Padova $H$, et al. Association between vaccination with BNT162b2 and incidence of symptomatic and asymptomatic SARS-CoV-2 infections among Health Care Workers. J Am Med Assoc. 2021;325:2457-65. https://pubmed.ncbi.nlm.nih.gov/33956048/

37. Swift MD, Breeher LE, Tande AJ, Tommaso $C P$, Hainy $C M$, Chu $H$, et al. Effectiveness of messenger RNA coronavirus disease 2019 (COVID-19) vaccines against severe acute respiratory syndrome coronavirus 2 (SARS-CoV-2) infection in a cohort of healthcare personnel. Clin Infect Dis. 2021;73:e1376-9.

38. Vijenthira A, Gong IY, Fox TA, Booth S, Cook G, Fattizzo B, et al. Outcomes of patients with hematologic malignancies and COVID-19: a systematic review and meta-analysis of 3377 patients. Blood. 2020;136:2881-92. https://pubmed.ncbi. nlm.nih.gov/33113551/

39. Malard F, Gaugler B, Gozlan J, Bouquet L, Fofana D, Siblany L, et al. Weak immunogenicity of SARS-CoV-2 vaccine in patients with hematologic malignancies. Blood Cancer J. 2021;11. https://pubmed.ncbi.nlm.nih.gov/34376633/

40. Tregoning JS, Flight KE, Higham SL, Wang Z, Pierce BF. Progress of the COVID-19 vaccine effort: viruses, vaccines and variants versus efficacy, effectiveness and escape. Nat Rev Immunol. 2021;21:626-36. https://pubmed.ncbi.nlm.nih.gov/ 34373623/

41. Sun L, Warner JL, Parikh RB. Immune responses to SARS-CoV-2 among patients with cancer: what can seropositivity tell us? JAMA Oncol. 2021;7:1123-5. https:// pubmed.ncbi.nlm.nih.gov/34047766/

42. Steensels D, Pierlet N, Penders J, Mesotten D, Heylen L. Comparison of SARS-CoV2 antibody response following vaccination with BNT162b2 and mRNA-1273. JAMA. 2021;326:1533-5. https://jamanetwork.com/journals/jama/fullarticle/ 2783797

43. Monin L, Laing AG, Muñoz-Ruiz M, McKenzie DR, del Molino del Barrio I, Alaguthurai $T$, et al. Safety and immunogenicity of one versus two doses of the COVID-19 vaccine BNT162b2 for patients with cancer: interim analysis of a prospective observational study. Lancet Oncol. 2021;22:765-78. https://pubmed. ncbi.nlm.nih.gov/33930323/ 
44. Ehmsen S, Asmussen A, Jeppesen SS, Nilsson AC, Østerlev S, Vestergaard H, et al. Antibody and T cell immune responses following mRNA COVID-19 vaccination in patients with cancer. Cancer Cell. 2021;39:1034-6. https://pubmed.ncbi.nlm.nih. gov/34348121/

45. Lederer K, Castaño D, Gómez Atria D, Oguin TH, Wang S, Manzoni TB, et al. SARSCoV-2 mRNA vaccines foster potent antigen-specific germinal center responses associated with neutralizing antibody generation. Immunity. 2020;53:1281-.e5. https://pubmed.ncbi.nlm.nih.gov/33296685/

46. Painter MM, Mathew D, Goel RR, Apostolidis SA, Pattekar A, Kuthuru O, et al Rapid induction of antigen-specific CD4+ T cells is associated with coordinated humoral and cellular immunity to SARS-CoV-2 mRNA vaccination. Immunity. 2021;54:2133-.e3. https://pubmed.ncbi.nlm.nih.gov/34453880/

47. Ghandili S, Schönlein $M$, Lütgehetmann $M$, Schulze Zur Wiesch J, Becher $H_{\text {, }}$ Bokemeyer $C$, et al. Post-vaccination anti-sars-cov-2-antibody response in patients with multiple myeloma correlates with low cd19+ b-lymphocyte count and anti-cd38 treatment. Cancers (Basel). 2021;13.

48. Perez C, Botta C, Zabaleta A, Puig N, Cedena MT, Goicoechea I, et al. Immunogenomic identification and characterization of granulocytic myeloid-derived suppressor cells in multiple myeloma. Blood. 2020;136:199-209. https://pubmed. ncbi.nlm.nih.gov/32325491/

49. Van Dongen JJM, Van Der Burg M, Kalina T, Perez-Andres M, Mejstrikova E, Vlkova $M$, et al. EuroFlow-based flowcytometric diagnostic screening and classification of primary immunodeficiencies of the lymphoid system. Front Immunol 2019;10. https://pubmed.ncbi.nlm.nih.gov/31263462/

50. Reynolds CJ, Pade C, Gibbons JM, Butler DK, Otter AD, Menacho K, et al. Prior SARS-CoV-2 infection rescues $B$ and $T$ cell responses to variants after first vaccine dose. Science (80). 2021;372:1418-23. https://pubmed.ncbi.nlm.nih.gov/ 33931567/

51. Goel RR, Apostolidis SA, Painter MM, Mathew D, Pattekar A, Kuthuru O, et al. Distinct antibody and memory $B$ cell responses in SARSCoV-2 naïve and recovered individuals following mRNA vaccination. Sci Immunol. 2021;6:1-19.
2015 Starting Grant (MYELOMANEXT 680200) and the CRIS Cancer Foundation (PR_EX 2020-02).

\section{AUTHOR CONTRIBUTIONS}

LETA, EMS, and BP were responsible for study conception and design. LETA, AMB, CM, A Zherniakova, C Guerrero, A Zabaleta, LB, CB, MAF, EMS, and BP developed study methodology. C Grande, AM, JMA, C Gomez, EPP, I Olazabal, I Oiartzabal, CP, FP, JFSM, and PRO provided study/material and/or patients. LETA, CM, C Guerrero, and EMS performed statistical analysis. LETA, AMB, CM, A Zherniakova, C Guerrero, EMS, and $\mathrm{BP}$ analyzed and interpreted the data. LETA, EMS, and BP wrote the manuscript. All authors reviewed and approved the manuscript.

\section{COMPETING INTERESTS}

The authors declare no competing interests.

\section{ADDITIONAL INFORMATION}

Supplementary information The online version contains supplementary material available at https://doi.org/10.1038/s41408-021-00594-1.

Correspondence and requests for materials should be addressed to Esperanza Martín-Sánchez or Bruno Paiva.

Reprints and permission information is available at http://www.nature.com/ reprints

Publisher's note Springer Nature remains neutral with regard to jurisdictional claims in published maps and institutional affiliations.

\section{ACKNOWLEDGEMENTS}

We particularly acknowledge the patients and health care practitioners for their participation in this study. We also acknowledge the Biobank of the University of Navarra for its collaboration, together with Astrid Cuellar, Andrea Jimenez, Jaione Larraiotz, Judith Martinez, and Laura Gutierrez for outstanding performance of flow cytometry immunophenotyping throughout the COVID-19 pandemic, and Goretti Azparren for administrative support in the execution of this project. This work was supported by the Centro de Investigación Biomédica en Red - Área de Oncología del Instituto de Salud Carlos III (CIBERONC; CB16/12/00369 and CB16/12/00489), Instituto de Salud Carlos III/Subdirección General de Investigación Sanitaria and cofinanced by European Regional Development Fund-FEDER "A way to make Europe" (FIS No. PI17/01243, PI20/00048), Departamento de Salud de Gobierno de Navarra (0011-3638-2020-000004), Asociación Española Contra el Cáncer (FCAECC, INVES211176MART), the Cancer Research UK [C355/A26819], FCAECC, and AIRC under the Accelerator Award Program (EDITOR), the European Research Council (ERC)

\begin{abstract}
(i) Open Access This article is licensed under a Creative Commons Attribution 4.0 International License, which permits use, sharing, adaptation, distribution and reproduction in any medium or format, as long as you give appropriate credit to the original author(s) and the source, provide a link to the Creative Commons license, and indicate if changes were made. The images or other third party material in this article are included in the article's Creative Commons license, unless indicated otherwise in a credit line to the material. If material is not included in the article's Creative Commons license and your intended use is not permitted by statutory regulation or exceeds the permitted use, you will need to obtain permission directly from the copyright holder. To view a copy of this license, visit http://creativecommons. org/licenses/by/4.0/.
\end{abstract}

(c) The Author(s) 2021

\section{THE ASOCIACIÓN VASCO-NAVARRA DE HEMATOLOGÍA Y HEMOTERAPIA (ASOVASNA) COOPERATIVE GROUP}

Luis-Esteban Tamariz-Amador ${ }^{4}$, Clara Gomez ${ }^{5}$, Ernesto Perez-Persona ${ }^{6}$, Iñigo Olazabal ${ }^{7}$, Itziar Oiartzabal ${ }^{8}$, Carlos Panizo ${ }^{1}$, Felipe Prosper (10', Jesus F. San-Miguel (1) ${ }^{1}$ and Paula Rodriguez-Otero ${ }^{1}$ 